\title{
Inheritance and Development of Martial Arts Culture in Heluo Area from the Perspective of Sports Culture
}

\author{
Zhou Jingkun \\ Huanghe S\&T College \\ Zhengzhou, Henan Province, China \\ francis88821@126.com
}

\author{
Zhou Minghua \\ Luoyang Normal University \\ Luoyang, Henan Province, China \\ lync-zhmh@163.com
}

\begin{abstract}
Heluo culture, as one of the sources of Chinese civilization, plays an important role in national culture. At the same time, Heluo's martial arts culture, as an important part of Chinese martial arts culture, makes martial arts become an important carrier of national culture through the inheritance and development. This paper analyzes the development of martial arts culture in Heluo area from the perspective of sports culture, so as to analyze the inheritance of martial arts culture in sports field, sports system and sports spirit culture in Heluo area. Through the study, problems of development and inheritance of martial arts in Heluo area are mainly reflected in three aspects: in the sports technical and cultural aspects, qualified inheritors and professional training places are inadequate; in the sports system culture, the government's attention is not high; in the sports spirit and culture, the inheritance thinking of inheritors is too old, causing some martial arts projects are facing the situation of loss. Through developing inheritor protection system, strengthening the martial arts culture propaganda and liberating the successor thought and other measures, the martial arts culture in the Heluo area can continue to be developed and inherited.
\end{abstract}

Keywords—sports culture; martial arts culture; Heluo area; inheritance and development

\section{CONTENT STRUCTURE OF SPORTS CULTURE}

The sports culture is a kind of culture in essence. Before discussing the contents of sports culture, first explain the meaning of culture. Human society is complex and diverse. Therefore, different disciplines and different scholars also have a variety of understandings on the concept of culture. But in general, the culture has the broad and narrow meaning. The broad culture refers to the sum of material wealth and spiritual wealth created in the process of human's social history practice. While the narrow culture refers to the human spirit, philosophy, religion, morality, law, science, technology, literature, art and social psychology, customs and so on. At present, cultural studies categorize the broad cultures into multiple methods: two-level, three-level, four-level and five-level. [1] This study uses a three-level method. The various components of culture organically form a cultural system; the components are in different positions in the entire cultural system and have different status. For example, three-level classification method is used to divide culture into contents in three levels: material and technological culture, organizational system culture and ideological culture. Then in the entire cultural system, the outermost layer is material and technological culture, the middle layer is the organizational system culture, and the core of the core is the ideological culture, especially the values contained in the ideological culture, which is the center of the entire cultural system. Through the three-level classification, subdivide any kind of specific cultural form to get the culture of the technical layer, the system layer and the spiritual layer.

The definition of sports culture can also be described in both general and narrow sense. From the broad sense, sports culture, including material wealth and spiritual wealth, is produced in the practical process where people consciously design and transform the physiological characteristics of the human body; from the narrow sense, sports culture is part of the sports ideas (spirit ). Through the cultural three-level classification, broad sports culture should be divided into the material and technical level in broad culture. The composition of a complex sports culture system should include the content of the broad sports culture. Corresponding to the cultural interpretation system, the broad sports culture can be divided into three levels: sports material culture, sports system culture and sports ideology. Specifically, the first level of sports material technology culture include sports technology, sports venues and equipment facilities; the second level of sports system culture generally include sports institutions and sports development strategies, guidelines, such as sports organization management system, competition system, competition rules and sports morality; the third level of sports ideas and culture should include sports value orientation, sports ideas, sports aesthetic taste and so on.

\section{DeVElopment OF Traditional Martial ARTS IN HELUO AREA}

A. The Development of Traditional Martial arts Culture in Heluo Area from the Perspective of Sports Technology Culture

Luoyang area is an ancient cultural center; Huaxia civilization originated here. As the central area of Heluo culture, the cultural atmosphere of Heluo region is strong, which also gave birth to a variety of martial arts culture. The martial arts boxing species in Luoyang area are rich and varied, up to dozens of species. Boxing types that originated in the Luoyang region or developed here include Nanwu boxing; Luoyang 
mind Liuhe boxing and Song pass back boxing and so on. [2] The boxing competition or martial arts performances popular nowadays are also brilliant.

Luoyang area hit the world Guinness Book of Records in 2004 due to boxing performance, such as the 10,000-people tai chi of "playing tai chi in the passionate Heluo". The martial arts competitions in Luoyang are very lively. Annually the fixed martial arts competition will be held for up to 6 times. There are also the display activities of martial arts projects, such as the Heluo Culture Festival and various temple fairs, which are the platform for the are martial arts to show.

\section{B. The Development of Traditional Martial Arts Culture in Heluo Area from the Perspective of Sports System Culture}

Luoyang region, due to a strong cultural heritage and a cultural atmosphere of a long history, lays much emphasis on traditional culture. Luoyang area also introduces martial arts into the school education. Schools and martial arts groups have carried out "martial arts into the campus" activities. Multiple schools regard martial arts as the main characteristics of its education and several schools integrate martial arts into the campus' special activities through other forms. [3] Luoyang students have a more direct understanding of martial arts and a correct and profound understanding of martial arts culture, so as to cultivate students' love for martial arts, strengthen the students' basic skills of martial arts techniques and also strengthen their bodies.

Luoyang Area has established a number of martial arts sites and martial arts branches; the number reaches up to hundreds. Only in Luoyang city, there are more than a hundred stations, which is of great significance for the martial arts' heritage and development, management and dissemination. There are mature martial arts education systems and groups in Luoyang area and the number of martial arts schools in large, with many forms. Because of its special geographical location and traditional martial arts cultural advantages, it is conducted in a large scale. However, with the socio-economic and cultural development and education reform, the number of martial arts schools began to shrink.

The temple cultural activities in Luoyang Area are wonderful in diverse forms, reflecting the integration of the culture. In its early days, temple fair was just a kind of ritual activities. But under the collision and integration of the folk culture and other traditional cultures, the temple fair has become a grand entertainment activity; martial arts activities have thus become an important protagonist of the temple fair, shining brilliantly in the temple activities. Temple fair will be carried out every year in the Luoyang area. There are over 100 temple fairs with different themes in different regions in one year. The number of temple fair with great characteristics and connotations is also large. Such temple fairs generally attract more people, such as the Luanchuan Laojunshan Temple Fair held on April 8, Guanlin Temple Fair to commemorate the loyalty and bravery spirit of Guan Gong, Heluo cultural temple held in the Spring Festival, Luoyang folk cultural temple related to peony flowers and so on.

In the wonderful lively temple fairs mentioned above, martial arts performance has always been the characteristic activity that attracts everyone's attention and wins favor from the public. Many martial arts performances are shown as the focus of temple fair; the most common types are tai chi and competition projects, and folk traditional martial arts less participates in the fair. In 2012, Nanwu boxing was shown on Heluo cultural temple fair and Heluo cultural tourism festival; through the temple performances, the public realized the characteristics of Nanwu boxing. The temple fair is also a large platform for martial arts show; traditional folk martial arts are quite distinctive. Through the temple show, it can be introduced to the community, causing people's attention and promoting people's understanding of traditional folk martial arts, which plays an important role in the traditional development and dissemination of traditional folk martial arts.

\section{The Development of Traditional Martial Arts Culture in Heluo Area from the Perspective of Sports Spiritual Culture}

Folk martial arts have a strong development potential in the Heluo area. Under the joint collision of the rich traditional martial arts, the martial arts have developed a broad pattern in Heluo area. It has formed the three martial arts systems with Shaolin boxing, tai chi, Chang boxing as the main contents. In the strong traditional cultural atmosphere of Heluo, the development of Heluo martial arts is not only that of boxing technique, but also the physical performance of Heluo culture, from which we can see Heluo ancestors' values of martial arts and their loyal and humble national spirit. [4] The development of martial arts is deeply influenced by the philosophical system of Heluo culture, especially the theory of yin and yang formed in Heluo culture, philosophy of harmony between heaven and man, Tao and Qi. The martial arts culture that develops in this cultural atmosphere is obviously characteristic of yin and yang theory, heaven and earth unity, tao and qi.

\section{InHERITANCE Problems of Traditional Martial ARtS Culture in Heluo Area from the PERSPECTIVE of Sports CULTURE}

Through the study of the development of martial arts culture in terms of sports technique, sports system and sports spirit culture in Heluo area, this paper analyzes the existing problems of traditional martial arts culture in Heluo area.

\section{A. From the perspective of the sports technical culture, there are insufficient qualified training facilities of martial arts}

On the one hand, due to the limitations of the cultural level of folk martial arts boxer, martial arts' boxing tradition is difficult to be passed down the scientific and rigorous and clear words. The traditional martial arts are accustomed to "words and deeds". Such a way of inheritance is limited to the energy and course selection of boxers and has higher dependence on the experienced old boxers. If the old boxers do not inherit the excellent boxing types in time, the excellent boxing will be lost with the death of the old boxers. And the inheritance of excellent boxing is difficult to realize.

On the other hand, the development of martial arts in today's society has formed the pattern with the competitive martial arts as the driving force. Therefore, a new generation of martial arts enthusiasts and inheritors do not have the power of learning folk martial arts and will not put a lot of energy into 
the study and practice of folk martial arts. In this martial arts atmosphere, the inheritance of folk martial arts began to face the risk of loss; the older generation of successors can't find enough qualified inheritors in the new generation of martial arts lovers.

In the early 80 s of the 20th century, martial arts films and television works such as "Shaolin Temple" where Jet Li starred were broadcast, so the general public began to have a longing for Chinese martial arts; the learning atmosphere of martial arts spread. During this period, the martial arts schools and pavilions have been developed; many martial arts personnel to run the martial arts schools and folk martial arts have had a brief development and promotion. But the martial arts schools that started up rapidly have many problems, such as limited teaching content, cultural courses that can't be guaranteed. With the development of social economy and culture and the advancement of educational reform, the number of martial arts schools' enrollment dropped sharply, and many martial arts schools could not be maintained and were then closed. And the martial arts schools that maintained had non-professional martial arts practice venues because of financial problems and lacked martial arts practice facilities. Number of specialized martial arts staff gradually reduced; more of them regard the martial arts as amateur activities, which in turn makes excellent martial arts unable to find qualified inheritors.

\section{B. Inheritance Problems of Traditional Martial Arts Culture in Heluo Area from the Perspective of Sports System Culture}

In today's development model, traditional martial arts culture makes a lot of martial arts practitioners unable to gain the corresponding economic sources through martial arts. And because the martial arts can't get enough official attention, it produces the problems out of lack of finance. The teaching of martial arts can't be guaranteed and civil martial arts activities and the game can't be carried out.

Due to the lack of specialized management institutions of civil martial arts, or the immature administrative system, it can't effectively organize and manage the traditional folk martial arts. And many folk martial arts are scattered in rural areas, which can't accept centralized management and protection. Traditional martial arts is likely to have chaotic development in such an atmosphere and it is difficult to effectively inherit the martial arts.

Folk martial arts are largely influenced by the traditional cultural concept. Some excellent old boxers' concepts are too old and there are many restrictions on the choice of inheritors. They believe that home martial arts should follow the rule of "father passing down to the son, son to the grandson, from generation to generation, ancestral secret, and passing inside rather than outside". This concept greatly limits the inheritance of traditional excellent martial arts, and even leads to loss.

\section{CONCLUSION}

Heluo's martial arts culture is as an important part of Chinese martial arts culture; it also plays an important role in the national culture and is an important carrier of national culture. At present, the martial arts culture in Heluo region is faced with the lack of inheritors and professional training places, insufficient government's attention, old inheritance concepts of inheritors in its modernized development and inheritance. In order to make the martial arts culture in Heluo region have better development and inheritance, we must first develop and improve the inheritance protection system, so that the traditional martial arts projects and culture can be protected and continued; second, strengthen the martial arts culture propaganda and form specialized martial arts management institutions; finally, liberate thinking of inheritors and break the former concepts of passing down to man rather than woman, to inside than outside, so as to make the excellent traditional martial arts project can be inherited and developed.

\section{REFERENCES}

[1] Zhu Yacheng. Several Discussions of “13th Five-year Plan” of Sports Development. Journal of Nanjing Institute of Physical Education(Social Science Edition) - 2016, 30(3) (In Chinese)

[2] Fan Qinggang. On Inheritance and Innovation of Traditional Martial Arts Culture in College Physical Education Teaching [J]. Chinese Journal of Education, 2015: 24-25. (In Chinese)

[3] Fu Jing. Research on the Inheritance of Traditional Martial Arts Culture in Martial Arts Teaching in Colleges and Universities [J]. Contemporary Sports Science and Technology. 2013 (33): 56-57. (In Chinese)

[4] Guo Shufen. Study on the Inheritance and Development of Folk Martial Arts in Luoyang Area under the View of Heluo Culture [M]. Chengdu Institute of Physical Education, 2013. (In Chinese) 